\title{
Review of studies on metabolic genes and cancer in populations of African descent
}

\author{
Camille C. Ragin, PhD, MPH ${ }^{1,2}$, Scott Langevin, BSc, MHA ${ }^{2}$, Scott Rubin ${ }^{2}$, \\ and Emanuela Taioli, $M D, P h D^{1,2}$
}

\begin{abstract}
Genetic polymorphisms described for a number of enzymes involved in the metabolism of tobacco carcinogens and alcohol have been linked to increase cancer risk. Racial disparities in cancer between whites and populations of African descent are well documented. In addition to differences in access to health care, both environment and genetic factors and their interaction may contribute to the increased cancer risk in minority populations. We reviewed the literature to identify case-control studies that included subjects of African descent. Meta-analyses investigating the association of genetic polymorphisms in tobacco metabolic genes and cancer were performed. Although several genes and cancers have been studied, only one or two studies per gene for each cancer site have been published, with the exception of breast (CYP1A1 and CYP1B1), lung (GSTM1, CYP1A1, and NQO1), and prostate (CYP3A4 A293G and CYP17). Marginal statistically significant associations were observed for CYP3A4 A293G and CYP17 $5^{\prime} U T R$ polymorphisms and prostate cancer. Our findings support the need for additional genetic association studies of breast, prostate, and lung cancers that include a larger number of minority participants. Because incidence and mortality rates for these cancers rank highest among populations of African descent, concentrated research in these areas are warranted. Genet Med 2010:12(1):12-18.
\end{abstract}

Key Words: cancer, Africans, African-Americans, genetic susceptibility

$\mathrm{P}$ hase I and Phase II metabolic genes encode important enzymes in the metabolism of tobacco carcinogens. Phase I enzymes are responsible for converting chemicals into compounds that bind mainly with DNA, thus being genotoxic. An example of Phase I enzymes is the Cytochrome P-450(CYP) family, which play a major role in tobacco carcinogen activation. Phase II enzymes are involved in the cellular detoxification of many carcinogens. The glutathione $S$-transferase (GSTM1, GSTP, and GSTT1) is an example of a Phase II enzyme. Substrates for GSTs include acetaldehyde, an alcohol metabolite, and several intermediate metabolites of polyaromatic hydrocarbons found in tobacco smoke. Genetic polymorphisms have

From the ${ }^{1}$ Department of Epidemiology, State University of New York Downstate Medical Center, New York; and ${ }^{2}$ Department of Epidemiology, University of Pittsburgh Graduate School of Public Health, Pennsylvania.

Camille C. Ragin, PhD, MPH, Department of Epidemiology, SUNY Downstate Medical Center, 450 Clarkson Avenue, Box 43, Brooklyn, NY 11203. E-mail: camille.ragin@downstate.edu.

Supplemental digital content is available for this article. Direct URL citations appear in the printed text and are provided in the HTML and PDF versions of this article on the journal's Web site (www.geneticsinmedicine.org).

The contents of this article are solely the responsibility of the authors and do not necessarily represent the official view of NCRR or NIH.

Disclosure: The authors declare no conflict of interest.

Submitted for publication June 8, 2009.

Accepted for publication November 1, 2009.

Published online ahead of print December 18, 2009.

DOI: $10.1097 /$ GIM.0b013e3181c8e160 been described for a number of enzymes involved in the metabolism of tobacco carcinogens and alcohol, and many of these polymorphisms have been linked to phenotypic differences in enzyme activity or expression..$^{1,2}$ Differences in the metabolic activation and detoxification pathways of these metabolic genes are likely to be a major source of interindividual variation in cancer susceptibility. However, in the absence of the main exposure (such as tobacco smoke), the contribution of these genetic factors is likely relevant. Genetic polymorphisms modulate the association observed between exposure (such as tobacco smoke) and cancer. Therefore, gene-environment interactions must be considered when evaluating the associations between exposures and diseases.

Racial disparities in cancer risk between whites and populations of African descent have been well documented in the United States. Between 1975 and 2006, the age-adjusted incidence rates for all cancer sites combined were 466.6/100,000 for whites and 505.9/100,000 for African-Americans. ${ }^{3}$ In addition to differences in access to health care, it is likely that both environment and genetic factors and their interaction contribute to the increased cancer risk observed in minority populations. However, few studies addressing gene-environment interactions have been conducted. For a number of cancer types, casecontrol studies have reported that polymorphisms in tobacco metabolic genes are associated with cancer risk, ${ }^{4-6}$ but investigations of these associations according to ethnic background are limited. Some case-control studies include smaller numbers of African-American subjects compared with whites, therefore are unable to report meaningful results for African-Americans because of lack of statistical power. For example, a previous pooled analysis of case-control studies evaluating the association of GSTM1 and CYP1A1 polymorphisms in oral and pharyngeal cancer reported no overall association, although the odds ratio (OR) in 294 African-Americas and Africans cases combined was almost 2.0.7 We have systematically reviewed the literature to identify all case-control studies that have included subjects of African ancestry and provided a summary of these existing studies. We have also performed meta-analyses investigating the association of genetic polymorphisms in tobacco metabolic genes and cancer risk in populations of African descent.

\section{METHODS}

\section{Selection criteria}

A Medline literature search for case-control and nested casecontrol studies published between 1966 and October 5, 2009, on the association of metabolic gene polymorphisms and any cancer in populations of African descent was conducted using the search term: (African-American or African) and (gene or polymorphism) and cancer. Only studies published in English, French, Spanish, or Italian and reporting genotypes for incident cases and controls using polymerase chain reaction methods were included in this review. Genes included were both Phase I and Phase II metabolic genes. The search yielded 80 original 
articles. Studies that did not provide race-specific genotype data by cases and controls were excluded from the analysis. Overlap of study subjects was evaluated by comparing sources of data described in the published methods and through crossreferencing using the Genetic Susceptibility to Environmental Carcinogens database (www.gsec.net). ${ }^{8}$ In the case of multiple publications reporting overlapping data, the more inclusive study was retained. An additional search was performed with each gene polymorphism identified from the first search along with alternative names and (variant or polymorphism) and cancer. This search yielded 19 additional studies.

Of the 99 publications, three were excluded because data on subjects of African descent was combined with those of mixed ancestry $^{9-11}$; three publications presented data that overlapped with more inclusive publications from the same authors ${ }^{12-14}$; seven did not provide race-specific genotype data ${ }^{15-21}$; three provided allele frequencies only ${ }^{22-24}$; one did not report genotype data for the controls ${ }^{25}$; two studies reported only on haplotypes ${ }^{26,27}$; and one was a methylation study and did not report on gene polymorphisms. ${ }^{28}$ After exclusions, 79 studies remained for consideration in this review and meta-analysis (see Table, Supplemental Digital Content 1, http://links.lww.com/GIM/A91, which describes the publications included in this study).

\section{Statistical analysis}

Study-specific crude ORs and 95\% confidence intervals (CIs) were recalculated to assess the association of each metabolic gene polymorphism and cancer, based on the reported genotype data by cases and controls. Meta-analytical techniques were applied for all metabolic gene polymorphisms reported in three or more studies using inverse-variance weighting to calculate the fixed and DerSimonian and Laird weighting to calculate random effects summary estimates. ${ }^{29}$ Random effects summary estimates were reported only when between-study heterogeneity was observed. Heterogeneity was evaluated using a $Q$-statistic, with significance considered at $P<0.10,30$ and $I^{2}$ metric and $95 \%$ CI to measure the percent variation in the OR because of heterogeneity. ${ }^{31,32} I^{2}$ values that are $50 \%$ or higher indicate large between-study heterogeneity, whereas values of $25-50 \%$ indicate moderate between-study heterogeneity. In the absence of statistical heterogeneity, the summary or meta-OR and corresponding $95 \%$ CI were reported based on the fixed effects model; when heterogeneity was observed, the results from the random effects model were reported. Corresponding forest plots were generated for a visual representation of all meta-analyses. The overall estimate and CI reported in the figures represent the meta-OR and CI. The Harbord test ${ }^{33}$ was used to test for small-study effects, with significance considered at $P<0.10$. The definition of race was self-reported in the studies included in this analysis, and African-American populations have various degrees of admixture. In an attempt to create homogeneous groups for analysis, differences in genotype frequencies between African-Americans and other African control populations were tested for the genes, which were included in the metaanalysis. Tests on the equality of proportions were performed for each group, and summary ORs were reported separately. In addition, stratified analyses according to geographic areas were performed where possible. All statistical analyses were carried out using STATA SE, version 10, software (StataCorp LP, College Station, TX).

\section{RESULTS}

We have summarized the studies that have reported data for various polymorphisms in populations of African descent and grouped according to cancer type (see Table, Supplemental Digital Content 1, http://links.lww.com/GIM/A91, which describes the publications included in this study). For breast cancer, 20 polymorphisms have been studied, but for 16 of the polymorphisms $(79 \%)$ only one or two studies were conducted. There were three studies on CYP1A1 Ile/Val, four studies on CYP1B1 V432L, and five studies each on CYP1A1 Mspl and CYP1A1 African-American-specific (AA specific) polymorphisms. For lung cancer, 18 polymorphisms have been studied, but for 14 of the polymorphisms (78\%), only one or two studies were published. There were seven studies on CYP1A1 Msp1, four studies each on GSTM1 deletion and NQO1 (C609T), and three studies on CYP1A1 (AA specific) polymorphisms. For prostate cancer, 27 polymorphisms have been studied, but for 25 of them (95\%), only one or two studies have reported data. There were four studies on CYP3A4 $(A 293 G)$ and five studies on CYP17 (5'UTR). For all other cancers (bladder, pancreas, kidney, head and neck, colon, brain, ovarian, esophagus, and leukemia), there was one or two publications for each polymorphism.

When looking at the genes for which only one or two studies reported data, there was no significant association between the polymorphism and the corresponding cancer, except for one study of GSTT deletion and prostate cancer showing an OR of $0.5(95 \% \mathrm{CI}=0.8-0.88)^{34}$; a single study of CYP1B1 (R48G) (OR: 2.22; 95\% CI = 1.01-5.09), CYP17 (rs 17115144) (OR: 3.92; 95\% CI = 1.04-14.43), CYP19 (rs1 1636639) (OR: 2.36; 95\% CI $=1.10-5.05), C Y P 19($ rs 3751592) $(\mathrm{OR}: 2.88 ; 95 \%$ $\mathrm{CI}=1.39-6.03)$, and $C Y P 27 B 1(\mathrm{OR}: 0.29 ; 95 \% \mathrm{CI}=0.08-$ 0.88 ) and prostate cancer ${ }^{35}$; one study of $C Y P 3 A 43$ (P340A) and prostate cancer (OR: $3.54 ; 95 \% \mathrm{CI}=1.36-9.94)^{36}$; one study of CYP17 (5'UTR) and lung cancer (OR: 3.03 ; 95\% CI $=1.19-$ $8.17)^{37}$; and one study of $A D H 2 * 3$ (R370C) and $A L D H 2 * 2$ $(Q 487 K)$ polymorphisms and esophageal cancer (OR: 2.19; 95\% CI $=1.23-3.90$ and OR: 9.26; $95 \% \mathrm{CI}=1.16-419.64$, respectively). ${ }^{38}$

\section{Meta-analysis \\ GSTM1 deletion}

For all cancers, 17 publications reported data on populations of African descent, for a total of 1437 cancer cases and 2026 controls. A meta-estimate of cancer risk with the GSTM1 deletion was only possible for lung cancer since four studies were conducted (497 cases and 624 controls). The source of controls was for the most part the healthy population (three of four studies), and all the subjects were African-American. The meta-OR was 1.26 (95\% CI: 0.96-1.65). There was no statistical evidence of heterogeneity among the four studies on lung cancer $\left(Q: 3.47 ; P=0.324 ; I^{2}=14 \%, 95 \% \mathrm{CI}: 0-87\right)$ or small-study effect $(P=0.548)$.

\section{CYP1A1 Msp1}

For all cancers, there were 14 studies on CYPIAl Mspl polymorphism and cancer in populations of African descent, for a total of 1782 cases and 2213 controls. Seven studies were conducted on lung cancer (960 cases and 1189 controls) and five on breast cancer ( 763 cases and 864 controls).

For lung cancer, four of the seven studies (57\%) involved controls from the healthy population. Five included AfricanAmerican subjects ${ }^{37,39-42}$ and two included subjects from Brazil. ${ }^{43,44}$ There was no significant difference in the frequency of the CYP1A1 Mspl polymorphism between African-Americans and Brazilians (42.5\% vs. $43.7 \%, P=0.847)$. The ORs for the CYP1A1 Mspl variant in the two Brazilian studies were both 
increased but not significant, and there was no overall association between the CYP1A1 Mspl homozygous variant and lung cancer in African-Americans (meta-OR: 0.93 ; 95\% CI: $0.62-$ 1.40). There was moderate heterogeneity between the AfricanAmerican studies $\left(Q\right.$ statistic: $6.19, P: 0.186 ; I^{2}=35.0 \%, 95 \%$ CI: $0-76)$ and no evidence of small-study effect $(P=0.943)$. There was also no overall association between the CYP1A1 Mspl heterozygotes and lung cancer (meta-OR: 1.00; 95\% CI: $0.82-1.21$ ), with no evidence of heterogeneity between studies ( $Q$ statistic: $3.48 ; P=0.481 ; I^{2}=0.0 \%, 95 \%$ CI: $\left.0-79\right)$, or of small-study effect $(P=0.379)$.

For breast cancer, four of the five studies involved AfricanAmerican subjects and controls from the healthy population (543 cases and 646 controls). ${ }^{45-48}$ The fifth study involved a Nigerian population with hospital controls (220 cases and 218 controls) ${ }^{49}$ There was no significant difference in the frequency of the CYP1A1 Mspl polymorphism between African-Americans and Africans from Nigeria (41.8\% vs. $40.37 \%, P=0.711)$. The meta-OR for the CYP1A1 Mspl homozygous variant in African-Americans (meta-OR: 1.19; 95\% CI: 0.71-1.99) was compared with the OR for the single African study (OR: 0.91; 95\% CI: 0.41-2.00), and neither was statistically significant. There was also no association between the CYP1A1 Mspl heterozygous variant with breast cancer in African-Americans (meta-OR: 0.95 ; 95\% CI: $0.74-1.22$ ) or in the single African study (meta-OR: 0.94; 95\% CI: 0.61-1.44). For African-Americans, there was evidence of large between-study heterogeneity for both the homozygous ( $Q$ statistic: $7.42 ; P=0.060 ; I^{2}=$ $60 \%, 95 \%$ CI: $0-87)$ and heterozygous $(Q$ statistic: $5.02 ; P=$ $\left.0.170 ; I^{2}=40 \%, 95 \% \mathrm{CI}: 0-80\right)$ variants but no evidence of small-study effect for either $(P=0.626 ; P=0.884)$.

\section{CYP1A1 lle/Val}

For all cancers combined, nine studies included separate results on populations of African descent, for a total of 1022 cases and 1692 controls. A meta-estimate of cancer risk with the CYP1A1 Ile/Val was only possible for breast cancer since three studies reported data for a total of 528 cases and 791 controls. The other cancers studied included ovarian, lung, pancreas, and head and neck cancers. All four breast cancer studies included African-Americans, and the source of controls was the healthy population. No significant association was reported in any individual study. A meta-estimate was only possible for the association of CYP1Al variant (Ile/Val and $\mathrm{Val} / \mathrm{Val}$ allele carriers combined) and breast cancer (meta-OR: 0.77 ; 95\% CI: $0.46-$ 1.30). There was no evidence of between-study heterogeneity ( $Q$ statistic: $2.50 ; P=0.286 ; I^{2}=20 \%, 95 \%$ CI: $\left.0-92\right)$ or small-study effect $(P=0.366)$.

\section{CYP1A1 African-American specific}

There were nine studies on the African-specific polymorphism (1123 cases and 1624 controls), for lung, breast, and ovarian cancer. Four studies reported data for breast cancer, and three studies reported data for lung cancer.

For breast cancer, four of the five studies included AfricanAmerican populations (542 cases and 645 controls) ${ }^{45-48}$ and the fourth included a Nigerian population (229 cases and 227 controls). ${ }^{49}$ The source of controls was the healthy population for all except for the Nigerian study. There was a significant difference in the frequency of this polymorphism between AfricanAmericans and Africans from Nigeria (15.8\% vs. $24.2 \%, P=$ $0.005)$. The summary estimate was calculated for the association of CYP1A1 (AA specific) variant (wt/var and var/var allele carriers combined) for African-Americans (meta-OR: 1.14;
95\% CI: 0.83-1.57) and was similar compared with the OR reported for Nigerians (OR: 0.94; 95\% CI $=0.60-1.48$ ).

For lung cancer, the three studies included African-American populations (319 cases and 626 controls), ${ }^{41,50,51}$ and all the controls were from healthy populations. The summary estimate was also calculated for the association of CYP1A1 (AA specific) variant (wt/var and var/var allele carriers combined) (meta-OR: 1.00 ; 95\% CI: $0.70-1.45)$. There was no evidence of heterogeneity among studies for lung ( $Q$ statistic: $1.65 ; P=0.438 ; I^{2}=$ $0.0 \%, 95 \% \mathrm{CI}: 0-90$ ), and there was moderate heterogeneity between the African-American breast cancer studies ( $Q$ statistic: $\left.5.61 ; P=0.132 ; I^{2}=47 \%, 95 \% \mathrm{CI}: 0-82\right)$. There was no evidence of small-study effect for neither lung $(P=0.294)$ nor breast $(P=0.985)$.

\section{CYP1B1 V432L}

For all cancers, combined six studies reported data separately for populations of African descent. Four were breast cancer studies, and three of the four studies involved hospital controls. There were three breast cancer studies that included African-

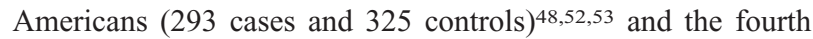
included a Nigerian population (228 cases and 226 controls). ${ }^{54}$ There was a significant difference in the frequency of this polymorphism between African-Americans and Africans from Nigeria (47.1\% vs. $19.5 \%, P<0.0001)$. Neither the AfricanAmerican studies nor the African study reported an association between the homozygote or heterozygote polymorphisms and breast cancer (data not shown). There was moderate heterogeneity between the African-American studies and no evidence of small-study effect (data not shown).

\section{NQO1 (C609T)}

Four studies on lung cancer and the NQO1 polymorphism in African populations were published and three of the four included healthy controls as comparison group (358 cases and 375 controls). All the studies included African-Americans. No association with lung cancer was reported for the NQO1 (C609T) variant $(C T+T T)$, (meta-OR: $0.91 ; 95 \% \mathrm{CI}=0.67-1.23)$, and there was no evidence of heterogeneity among the studies $(Q$ statistic: $0.68 ; P=0.878 ; I^{2}=0.0 \%, 95 \%$ CI: $\left.0-85\right)$ or small-study effect $(P=0.762)$.

\section{CYP3A4 (A293G)}

Four of the six studies involving the $A 293 G$ polymorphism of the $C Y P 3 A 4$ gene were conducted on prostate cancer, for a total of 608 prostate cases and 776 controls. The other two studies were on breast cancer. There is a consensus among studies on the association between the polymorphism and prostate cancer in populations of African descent. Three of the four prostate cancer studies included African-American ${ }^{55-57}$ populations only, whereas one included both African-American and Nigerian populations. ${ }^{58}$ There were 531 African-American cases and 694 controls, and there were 77 Nigerian cases and 82 controls. There was a significant difference in the frequency of the CYP3A4 (A293G) polymorphism (GG) between African-Americans and Africans from Nigeria $(41.2 \%$ vs. $74.4 \%, P<$ 0.0001). Although there was no association of CYP3A4 A293G homozygote variant and prostate cancer in Nigerians (OR: 0.3; $95 \% \mathrm{CI}=0.01-3.63)$ or in African-Americans, the meta-OR was almost twofold (meta-OR: $1.55 ; 95 \% \mathrm{CI}=0.81-2.95$ ) for African-Americans (Fig. 1), but there was large between-study heterogeneity ( $Q$ statistic: $8.24 ; P=0.041 ; I^{2}=64.0 \%, 95 \%$ CI: $0-88)$ and no small-study effect $(P=0.231)$. Similarly, there was no association between $A 293 G$ heterozygous variants and prostate cancer for the Nigerian (OR: 0.38 ; $95 \%$ CI $=$ 


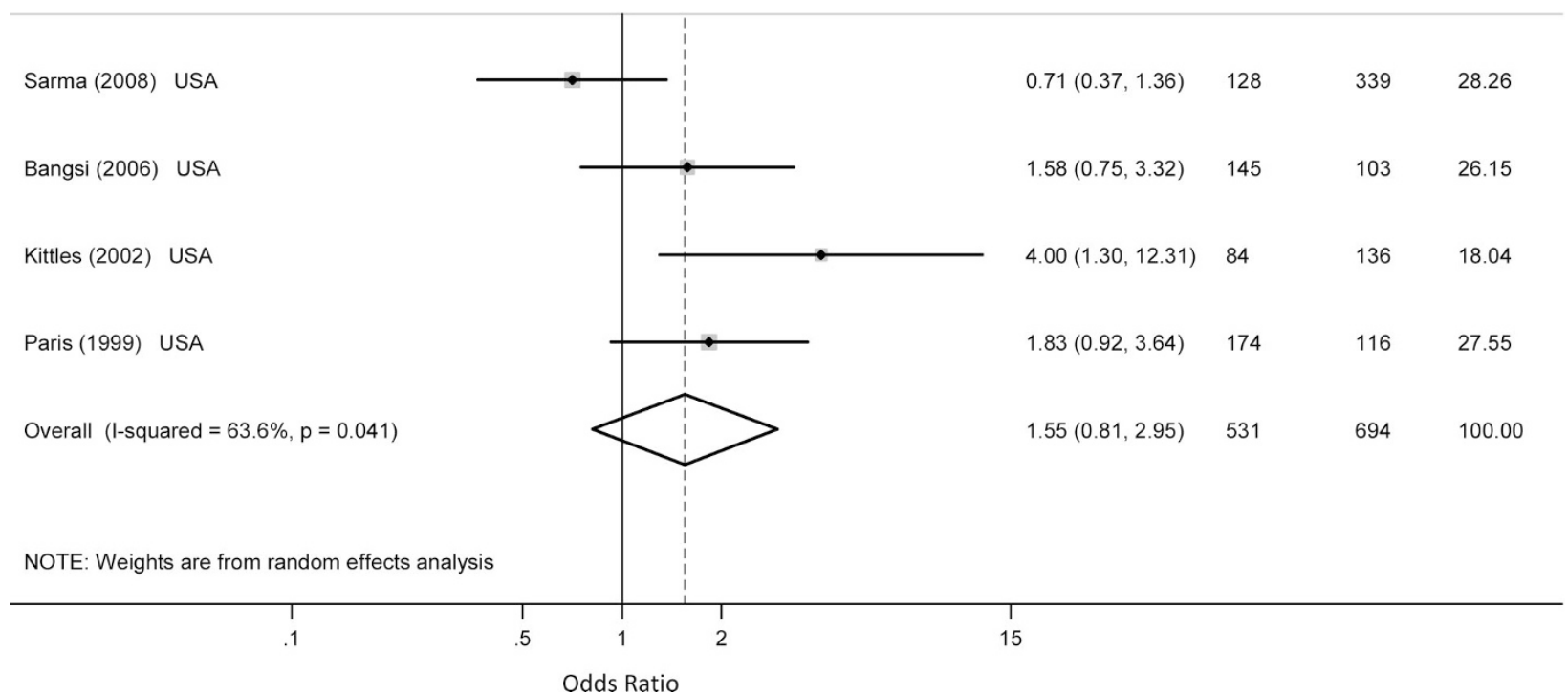

Fig. 1. Published case-control studies show a significant association of the CYP3A4 (A293G) homozygous variant and prostate cancer in African-Americans. The shaded boxes represent the study-specific odds ratios, and horizontal lines represent the confidence intervals; the size of the rectangles depict how each study is weighted in the analysis, and the diamond represents the meta-OR and its width represents the $\mathrm{Cl}$ for the meta-OR.

0.01-5.32) or the African-American (meta-OR: $1.26 ; 95 \% \mathrm{CI}$ : $0.72-2.20)$ studies. There was large heterogeneity between the African-American studies ( $Q$ statistic: $6.63 ; P=0.085 ; I^{2}=$ $55 \%, 95 \% \mathrm{CI}: 0-85)$ and evidence of small-study effect $(P=$ $0.05)$.

\section{CYP17 (5'UTR)}

For all cancers combined, eight studies reported data for the CYP17 5'UTR polymorphism (595 cases and 839 controls). Five studies were conducted on prostate cancer, for a total of 277 cases and 494 controls. ${ }^{55,59-62}$ Two studies were on breast cancer $^{48,63}$ and one study on lung cancer. ${ }^{37}$

All the prostate cancer studies included African-American populations. The homozygous variant polymorphism was marginally associated with prostate cancer (meta-OR: $1.56 ; 95 \%$ CI: 0.97-2.51), without evidence of heterogeneity among studies $\left(Q\right.$ statistics: $2.31 ; P=0.679 ; I^{2}=0.0 \%, 95 \%$ CI: $\left.0-79\right)$, or small-study effect $(P=0.759)$ (Fig. 2). There was no statistically significant association between the heterozygous variant and prostate cancer (meta-OR: 1.35 ; 95\% CI: $0.65-$ 2.80 ), although considerable between-study heterogeneity was present ( $Q$ statistics: $13.39 ; P=0.010 ; I^{2}=70 \%, 95 \% \mathrm{CI}$ : $24-88)$. There was no evidence of small-study effect $(P=$ $0.276)$.

\section{DISCUSSION}

This review of the literature indicates that although there is a wealth of studies on genetic polymorphisms and cancer risk, studies on populations of African descent are few. This observation is in contrast with the fact that for decades, underrepresented minorities have shown higher mortality rates than most other ethnic groups from cancer. ${ }^{64,65}$ Despite the fact that studies have shown that genetic susceptibility to tobacco carcino- gens increases individual cancer risk, ${ }^{66}$ information on individual susceptibility to tobacco and gene-environment interaction are lacking in subjects of African descent, mostly because they are underrepresented in current research studies. Therefore, it is not yet possible to determine whether association exists between a given genetic polymorphism and cancer risk in populations of African descent and the degree of interaction between such polymorphisms and environmental exposure.

In the United States, studies have investigated reasons for the underrepresentation of African-Americans in medical research. Shavers-Hornaday and Lynch ${ }^{67}$ reviewed the literature and reported that the reasons for underrepresentation of AfricanAmericans in research may be due to participant barriers such as distrust; poor access; quality and utilization of health care; lack of knowledge about clinical trials; language and culture; and investigator barriers, such as failure to actively recruit participants because of preexisting beliefs regarding the ability to recruit and retain participants; small number of minority research investigators; limited relationships between minority health care providers; and fears of how research results will be interpreted. Nevertheless, the successful recruitment and participation of African-Americans have been accomplished by some investigators, although these studies are few. Efforts to increase the number of represented minority participants in research studies are warranted.

We have shown that for each gene, there are several different cancer types that were studied. The majority of these include breast, prostate, and lung cancers, which are reported to be among the top four cancers with the highest incidence and mortality rates in African-Americans. ${ }^{3}$ Although several genes have been studied for various cancers, only one or two studies per gene for each cancer site have been published, with the exception of breast (CYP1A1 and CYP1B1), lung (GSTM1, CYP1A1, and NQO1), and prostate (CYP3A4 A293G and 
$\begin{array}{llll}\text { Study ID } & \text { OR }(95 \% \mathrm{Cl}) & \text { Cases } & \text { Controls Weight }(\%)\end{array}$

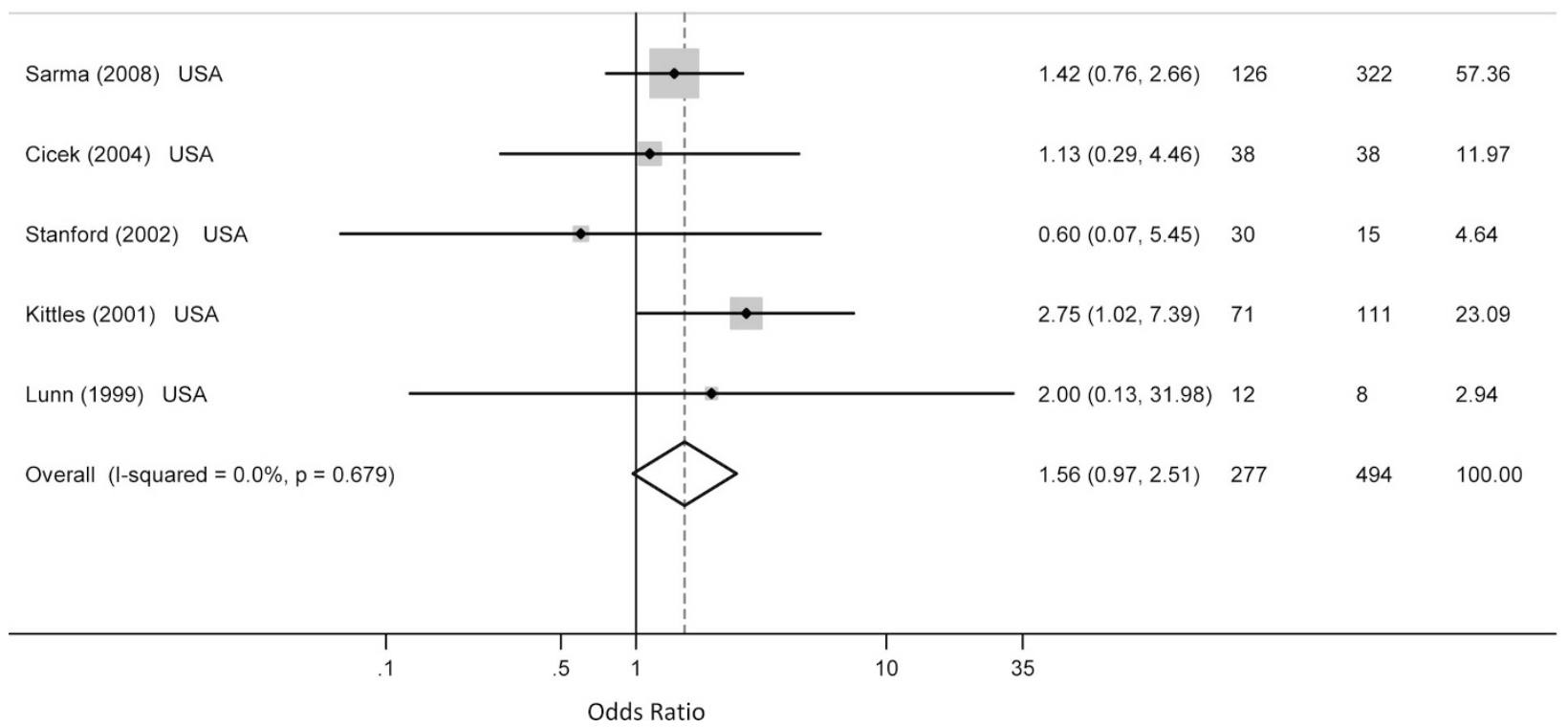

Fig. 2. Published case-control studies show a marginal significant association of the CYP17 5' UTR homozygous variant and prostate cancer in African-Americans. The shaded boxes represent the study-specific odds ratios, and horizontal lines represent the confidence intervals; the size of the rectangles depict how each study is weighted in the analysis, and the diamond represents the meta-OR and its width represents the $\mathrm{Cl}$ for the meta-OR.

CYP17). For the breast cancer studies that reported data for African-Americans and Africans, the frequencies of the CYP1A1 AA-specific and CYP1B1 V432L variants in the controls were significantly different between the two populations. Neither of the two populations showed statistically significant associations of these genes and breast cancer. It is possible that the difference in gene variant frequencies between the two African-descent populations might be attributed to admixture among African-Americans or to linkage disequilibrium with other relevant genetic polymorphisms, suggesting that further studies in African descent populations are needed.

For prostate cancer, a marginal association was observed for CYP3A4 A293G and CYP17 and prostate cancer in AfricanAmericans, whereas an inverse relationship was reported for CYP3A4 $A 293 G$ in the single Nigerian study. Our findings suggest that the differences in prostate cancer risk for $C Y P 3 A 4$ $A 293 G$ between African-Americans and Africans and the contribution of admixture in African-Americans needs further investigation. Studies of CYP3A4A293G and prostate cancer in whites report a marginally statistically significant increased $\mathrm{OR}^{56,58}$; two studies on CYP17 in whites show no association ${ }^{59,62}$; and one study reported an increased OR. ${ }^{61}$ Because of the small number of case-control studies in our meta-analyses, the reproducibility of the reported results for each cancer/gene association could not be evaluated, which made it difficult to interpret the reported results.

The CYP17 gene encodes an enzyme, which functions at key points in steroid hormone biosynthesis and metabolism pathways, ${ }^{68}$ and the polymorphism in the $5^{\prime}$-UTR is thought to affect hormone levels. High levels of androgens have been considered as risk factors for prostate cancer. ${ }^{69}$ However, the relationship between the CYP17 variant and increased hormone levels is inconclusive. ${ }^{70}$ In 2003, a meta-analysis on the association between the
CYP17 variant and prostate cancer was published and included 10 studies conducted in Europe, Asia, and the United States (2404 prostate cancer cases and 2755 controls). ${ }^{71}$ The report showed that the overall contribution of the CYP17 5'UTR polymorphism to prostate cancer risk was not evident; however, there were distinct differences based on ethnicity (European descent, OR: 1.04; 95\% CI, 0.92-1.18; Asian descent OR: 1.06; 95\% CI, 0.66-1.71; and African descent OR: 1.56 ; 95\% CI, 1.07-2.28). There were three studies in this meta-analysis, 113 cases and 134 controls. Although our meta-analysis includes much larger population (5 studies, 277 cases, and 494 controls), the findings from the earlier study was consistent with our findings and suggest a need for large-scale investigation of the association of the gene variant and prostate cancer risk in males of African descent. The gene product of CYP3A4 is involved in the oxidation of a large range of substrates including therapeutic drugs, steroids, fatty acids, and xenobiotics, and similar to $C Y P 17$, also plays a role in androgen metabolism. ${ }^{72}$ It is biologically plausible that both these genetic polymorphisms may play a significant role in prostate cancer risk. Further, larger studies of the association of these gene variants and prostate cancer in populations of African descent are warranted.

Overall our findings support the need for larger studies of CYP1A1 Mspl and breast cancer and CYP17 and CYP3A4 $A 293 G$ and prostate cancer in African descent populations. The development of large-scale, population-based databases that document genetic variation in tobacco-related genes among case and control subjects that represent populations of African ancestry would serve as an important resource for cancercontrol and prevention programs. Our findings support the need for additional genetic association studies of breast, prostate, and lung cancers that include larger number of minority participants and a better definition of African ancestry. Specifically, there is a need to concentrate research on these three major cancers, 
because incidence and mortality rank the highest among populations of African descent. Furthermore, specific research focus is needed on genes with a sound hypothesis related to cancer risk in subjects of African descent. Our review of the literature reveals that the majority of studies have been conducted in the United States, but still very few involve African or other populations of African ancestry such as African-Caribbean. This may be due to the limited financial and infrastructural resources available to conduct these studies. Nevertheless, it is clear that efforts to increase the number of studies in African descent populations outside of the United States are warranted.

\section{ACKNOWLEDGMENTS}

This work was supported in part by Grant number KL2 RR024154-03 from the National Center for Research Resources (NCRR), ${ }^{73}$ a component of the National Institutes of Health (NIH) and NIH Roadmap for Medical Research. ${ }^{74}$ The contents of this article are solely the responsibility of the authors and do not necessarily represent the official view of NCRR or NIH. This work was also supported in part by Grant number R13CA130596A to C.C.R. and P20CA132385-01 to E.T.

\section{REFERENCES}

1. Daly AK, Cholerton S, Armstrong M, Idle JR. Genotyping for polymorphisms in xenobiotic metabolism as a predictor of disease susceptibility. Environ Health Perspect 1994;102:55-61.

2. Thier R, Bruning T, Roos PH, et al. Markers of genetic susceptibility in human environmental hygiene and toxicology: the role of selected CYP, NAT and GST genes. Int J Hyg Environ Health 2003;206:149-171.

3. Ries LAG, Melbert D, Krapcho M, et al, editors. SEER cancer statistics review, 1975-2005. Bethesda, MD: National Cancer Institute, 2009.

4. Cote ML, Chen W, Smith DW, et al. Meta- and pooled analysis of GSTP1 polymorphism and lung cancer: a HuGE-GSEC review. Am J Epidemiol 2009;169:802-814.

5. Langevin SM, Lin D, Matsuo K, et al. Review and pooled analysis of studies on MTHFR C677T polymorphism and esophageal cancer. Toxicol Lett 2009;184:73-80.

6. Paracchini V, Raimondi S, Gram IT, et al. Meta- and pooled analyses of the cytochrome P-450 1B1 Val432Leu polymorphism and breast cancer: a HuGE-GSEC review. Am J Epidemiol 2007;165:115-125.

7. Varela-Lema L, Taioli E, Ruano-Ravina A, et al. Meta-analysis and pooled analysis of GSTM1 and CYP1A1 polymorphisms and oral and pharyngeal cancers: a HuGE-GSEC review. Genet Med 2008;10:369-384.

8. Gaspari L, Marinelli D, Taioli E. International collaborative study on genetic susceptibility to environmental carcinogens (GSEC): an update. Int J Hyg Environ Health 2001;204:39-42.

9. Hatagima A, Costa EC, Marques CF, Koifman RJ, Boffetta P, Koifman S. Glutathione S-transferase polymorphisms and oral cancer: a case-control study in Rio de Janeiro, Brazil. Oral Oncol 2008;44:200-207.

10. Honma HN, De Capitani EM, Perroud MW Jr, et al. Influence of p53 codon 72 exon 4, GSTM1, GSTT1 and GSTP1*B polymorphisms in lung cancer risk in a Brazilian population. Lung Cancer 2008;61:152-162.

11. Li D, Dandara C, Parker MI. Association of cytochrome P450 2E1 genetic polymorphisms with squamous cell carcinoma of the oesophagus. Clin Chem Lab Med 2005;43:370-375.

12. Li Y, Millikan RC, Bell DA, et al. Polychlorinated biphenyls, cytochrome P450 1A1 (CYP1A1) polymorphisms, and breast cancer risk among African American women and white women in North Carolina: a populationbased case-control study. Breast Cancer Res 2005;7:R12-R18.

13. Taioli E, Trachman J, Chen X, Toniolo P, Garte SJ. A CYP1A1 restriction fragment length polymorphism is associated with breast cancer in africanamerican women. Cancer Res 1995;55:3757-3758.

14. Wenzlaff AS, Cote ML, Bock CH, et al. CYP1A1 and CYP1B1 polymorphisms and risk of lung cancer among never smokers: a population-based study. Carcinogenesis 2005;26:2207-2212.

15. Feigelson HS, McKean-Cowdin R, Coetzee GA, Stram DO, Kolonel LN, Henderson BE. Building a multigenic model of breast cancer susceptibility: CYP17 and HSD17B1 are two important candidates. Cancer Res 2001;61: 785-789.

16. Kato S, Shields PG, Caporaso NE, et al. Cytochrome P450IIE1 genetic polymorphisms, racial variation, and lung cancer risk. Cancer Res 1992; $52: 6712-6715$.
17. Kato S, Shields PG, Caporaso NE, et al. Analysis of cytochrome P450 2E1 genetic polymorphisms in relation to human lung cancer. Cancer Epidemiol Biomarkers Prev 1994;3:515-518.

18. Le Marchand L, Wilkens LR, Kolonel LN, Henderson BE. The MTHFR C677T polymorphism and colorectal cancer: the Multiethnic Cohort Study. Cancer Epidemiol Biomarkers Prev 2005;14:1198-1203.

19. Le Marchand L, Donlon T, Kolonel LN, Henderson BE, Wilkens LR. Estrogen metabolism-related genes and breast cancer risk: the Multiethnic Cohort Study. Cancer Epidemiol Biomarkers Prev 2005;14:1998-2003.

20. Yuan JM, Lu SC, Van Den BD, et al. Genetic polymorphisms in the methylenetetrahydrofolate reductase and thymidylate synthase genes and risk of hepatocellular carcinoma. Hepatology 2007;46:749-758.

21. Park JY, Chen L, Elahi A, Lazarus P, Tockman MS. Genetic analysis of microsomal epoxide hydrolase gene and its association with lung cancer risk. Eur J Cancer Prev 2005;14:223-230.

22. Hawkins GA, Cramer SD, Zheng SL, et al. Sequence variants in the human 25-hydroxyvitamin D3 1-alpha-hydroxylase (CYP27B1) gene are not associated with prostate cancer risk. Prostate 2002;53:175-178.

23. Rao GG, Kurien A, Gossett D, Griffith WF, Coleman RL, Muller CY. A case-control study of methylenetetrahydrofolate reductase polymorphisms in cervical carcinogenesis. Gynecol Oncol 2006;101:250-254.

24. Wilborn TW, Lang NP, Smith M, Meleth S, Falany CN. Association of SULT2A1 allelic variants with plasma adrenal androgens and prostate cancer in African American men. J Steroid Biochem Mol Biol 2006;99: $209-214$

25. Zhu K, Hunter S, Payne-Wilks K, et al. Potential differences in breast cancer risk factors based on CYP1A1 MspI and African-American-specific genotypes. Ethn Dis 2006;16:207-215

26. Haiman CA, Stram DO, Pike MC, et al. A comprehensive haplotype analysis of CYP19 and breast cancer risk: the multiethnic cohort. Human Mol Genet 2003;12:2679-2692.

27. Setiawan VW, Cheng I, Stram DO, et al. A systematic assessment of common genetic variation in CYP11A and Risk of breast cancer. Cancer Res 2006;66:12019-12025.

28. Hoque MO, Feng Q, Toure P, et al. Detection of aberrant methylation of four genes in plasma DNA for the detection of breast cancer. J Clin Oncol 2006;24:4262-4269.

29. Egger M, Davey Smith G, Altman DG (eds). Systematic Reviews in Health Care: Meta-analysis in context, 2nd ed. London, UK: BMJ, 2001.

30. Whitehead A, Whitehead J. A general parametric approach to the metaanalysis of randomized clinical trials. Stat Med 1991;10:1665-1677.

31. Higgins JP, Thompson SG, Deeks JJ, Altman DG. Measuring inconsistency in meta-analyses. BMJ 2003;327:557-560

32. Ioannidis JP, Patsopoulos NA, Evangelou E. Uncertainty in heterogeneity estimates in meta-analyses. BMJ 2007;335:914-916.

33. Harbord RM, Egger M, Sterne JA. A modified test for small-study effects in meta-analyses of controlled trials with binary endpoints. Stat Med 2006;25:3443-3457.

34. Mallick S, Romana M, Blanchet P, Multigner L. GSTM1 and GSTT1 polymorphisms and the risk of prostate cancer in a Caribbean population of African descent. Urology 2007;69:1165-1169.

35. Beuten J, Gelfond JA, Franke JL, et al. Single and multigenic analysis of the association between variants in 12 steroid hormone metabolism genes and risk of prostate cancer. Cancer Epidemiol Biomarkers Prev 2009;18: 1869-1880.

36. Stone A, Ratnasinghe LD, Emerson GL, et al. CYP3A43 Pro340Ala polymorphism and prostate cancer risk in African Americans and Caucasians. Cancer Epidemiol Biomarkers Prev 2005;14:1257-1261.

37. Cote ML, Yoo W, Wenzlaff AS, et al. Tobacco and estrogen metabolic polymorphisms and risk of non-small cell lung cancer in women. Carcinogenesis 2009;30:626-635.

38. Li DP, Dandara C, Walther G, Parker MI. Genetic polymorphisms of alcohol metabolising enzymes: their role in susceptibility to oesophageal cancer. Clin Chem Lab Med 2008;46:323-328.

39. Ishibe N, Wiencke JK, Zuo ZF, McMillan A, Spitz M, Kelsey KT. Susceptibility to lung cancer in light smokers associated with CYP1A1 polymorphisms in Mexican- and African-Americans. Cancer Epidemiol Biomarkers Prev 1997;6:1075-1080.

40. Shields PG, Caporaso NE, Falk RT, et al. Lung cancer, race, and a CYP1A1 genetic polymorphism. Cancer Epidemiol Biomarkers Prev 1993; 2:481-485

41. Taioli E, Ford J, Trachman J, Li Y, Demopoulos R, Garte S. Lung cancer risk and CYP1A1 genotype in African Americans. Carcinogenesis 1998; 19:813-817.

42. Wrensch MR, Miike R, Sison JD, et al. CYP1A1 variants and smokingrelated lung cancer in San Francisco Bay area Latinos and African Americans. Int J Cancer 2005;113:141-147.

43. Sugimura H, Suzuki I, Hamada GS, et al. Cytochrome P-450 1A1 genotype in lung cancer patients and controls in Rio de Janeiro, Brazil. Cancer Epidemiol Biomarkers Prev 1994;3:145-148. 
44. Honma HN, De Capitani EM, Barbeiro AS, Costa DB, Morcillo A, Zambon L. Polymorphism of the CYP1A1*2A gene and susceptibility to lung cancer in a Brazilian population. J Bras Pneumol 2009;35:767-772.

45. Bailey LR, Roodi N, Verrier CS, Yee CJ, Dupont WD, Parl FF. Breast cancer and CYPIA1, GSTM1, and GSTT1 polymorphisms: evidence of a lack of association in Caucasians and African Americans. Cancer Res 1998;58:65-70.

46. Li Y, Millikan RC, Bell DA, et al. Cigarette smoking, cytochrome P4501A1 polymorphisms, and breast cancer among African-American and white women. Breast Cancer Res 2004;6:R460-R473.

47. Taioli E, Bradlow HL, Garbers SV, et al. Role of estradiol metabolism and CYP1A1 polymorphisms in breast cancer risk. Cancer Detect Prev 1999;23: 232-237.

48. Kato I, Cichon M, Yee CL, Land S, Korczak JF. African Americanpreponderant single nucleotide polymorphisms (SNPs) and risk of breast cancer. Cancer Epidemiol 2009;33:24-30.

49. Okobia M, Bunker C, Zmuda J, et al. Cytochrome P4501A1 genetic polymorphisms and breast cancer risk in Nigerian women. Breast Cancer Res Treat 2005;94:285-293.

50. Kelsey KT, Wiencke JK, Spitz MR. A race-specific genetic polymorphism in the CYP1A1 gene is not associated with lung cancer in African Americans. Carcinogenesis 1994;15:1121-1124.

51. London SJ, Daly AK, Fairbrother KS, et al. Lung cancer risk in AfricanAmericans in relation to a race-specific CYP1A1 polymorphism. Cancer Res 1995;55:6035-6037.

52. Bailey LR, Roodi N, Dupont WD, Parl FF. Association of cytochrome P450 1B1 (CYP1B1) polymorphism with steroid receptor status in breast cancer. Cancer Res 1998;58:5038-5041.

53. Van Emburgh BO, Hu JJ, Levine EA, et al. Polymorphisms in CYP1B1, GSTM1, GSTT1 and GSTP1, and susceptibility to breast cancer. Oncol Rep 2008;19:1311-1321.

54. Okobia MN, Bunker CH, Garte SJ, et al. Cytochrome P450 1B1 Val432Leu polymorphism and breast cancer risk in Nigerian women: a case control study. Infect Agent Cancer 2009;4(suppl 1):S12.

55. Sarma AV, Dunn RL, Lange LA, et al. Genetic polymorphisms in CYP17, CYP3A4, CYP19A1, SRD5A2, IGF-1, and IGFBP-3 and prostate cancer risk in African-American men: the Flint Men's Health Study. Prostate 2008;68:296-305.

56. Bangsi D, Zhou J, Sun Y, et al. Impact of a genetic variant in CYP3A4 on risk and clinical presentation of prostate cancer among white and AfricanAmerican men. Urol Oncol 2006;24:21-27.

57. Paris PL, Kupelian PA, Hall JM, et al. Association between a CYP3A4 genetic variant and clinical presentation in African-American prostate cancer patients. Cancer Epidemiol Biomarkers Prev 1999;8:901-905.

58. Kittles RA, Chen W, Panguluri RK, et al. CYP3A4-V and prostate cancer in African Americans: causal or confounding association because of population stratification? Hum Genet 2002;110:553-560.

59. Stanford JL, Noonan EA, Iwasaki L, et al. A polymorphism in the CYP17 gene and risk of prostate cancer. Cancer Epidemiol Biomarkers Prev 2002;11:243-247.

60. Kittles RA, Panguluri RK, Chen W, et al. Cyp17 promoter variant associated with prostate cancer aggressiveness in African Americans. Cancer Epidemiol Biomarkers Prev 2001;10:943-947.

61. Lunn RM, Bell DA, Mohler JL, Taylor JA. Prostate cancer risk and polymorphism in 17 hydroxylase (CYP17) and steroid reductase (SRD5A2). Carcinogenesis 1999;20:1727-1731.

62. Cicek MS, Conti DV, Curran A, et al. Association of prostate cancer risk and aggressiveness to androgen pathway genes: SRD5A2, CYP17, and the AR. Prostate 2004;59:69-76.

63. Weston A, Pan CF, Bleiweiss IJ, et al. CYP17 genotype and breast cancer risk. Cancer Epidemiol Biomarkers Prev 1998;7:941-944.

64. DeLancey JO, Thun MJ, Jemal A, Ward EM. Recent trends in black-white disparities in cancer mortality. Cancer Epidemiol Biomarkers Prev 2008; 17:2908-2912.

65. Piffath TA, Whiteman MK, Flaws JA, Fix AD, Bush TL. Ethnic differences in cancer mortality trends in the US, 1950-1992. Ethn Health 2001;6:105-119.

66. Taioli E. Gene-environment interaction in tobacco-related cancers. Carcinogenesis 2008;29:1467-1474

67. Shavers-Hornaday VL, Lynch CF, Burmeister LF, Torner JC. Why are African Americans under-represented in medical research studies? Impediments to participation. Ethn Health 1997;2:31-45.

68. Picado-Leonard J, Miller WL. Cloning and sequence of the human gene for P450c17 (steroid 17 alpha-hydroxylase/17,20 lyase): similarity with the gene for P450c21. DNA 1987;6:439-448.

69. Gann PH, Hennekens CH, Ma J, Longcope C, Stampfer MJ. Prospective study of sex hormone levels and risk of prostate cancer. J Natl Cancer Inst 1996;88:1118-1126.

70. Sharp L, Cardy AH, Cotton SC, Little J. CYP17 gene polymorphisms: prevalence and associations with hormone levels and related factors. A HuGE review. Am J Epidemiol 2004;160:729-740.

71. Ntais C, Polycarpou A, Ioannidis JP. Association of the CYP17 gene polymorphism with the risk of prostate cancer: a meta-analysis. Cancer Epidemiol Biomarkers Prev 2003;12:120-126.

72. Keshava C, McCanlies EC, Weston A. CYP3A4 polymorphisms-potential risk factors for breast and prostate cancer: a HuGE review. Am J Epidemiol 2004; $160: 825-841$.

73. National Institutes of Health. National Center of Research Resources, 2007. Available at: http://www.ncrr.nih.gov. Accessed December 4, 2009

74. NIH Roadmap for Medical Research, Re-engineering the Clinical Research Enterprise. Available at: http://nihroadmap.nih.gov/clinicalresearch/ overviewtranslational.asp. Accessed December 4, 2009. 